\title{
Cobalt-Catalyzed Electrophilic Aminations with Anthranils: An Expedient Route to Condensed Quinolines
}

\author{
Jie Li, ${ }^{*},+, \S^{\dagger}$ Eric Tan, ${ }^{\dagger \dagger}$ Niklas Keller, ${ }^{\dagger} \dagger$ Yi-Hung Chen, ${ }^{\dagger}$ Peter M. Zehetmaier, ${ }^{\dagger}$ \\ Andreas C. Jakowetz, ${ }^{\dagger}$ Thomas Bein, ${ }^{*}, \uparrow$ and Paul Knochel ${ }^{*}, \dagger$ \\ ${ }^{\dagger}$ Department Chemie, Ludwig-Maximilians-Universität München, Butenandtstraße 5-13, Haus F, 81377 Munich, Germany \\ ${ }^{\S}$ School of Pharmaceutical Science, Jiangnan University, Lihu Road 1800, 214122 Wuxi, Jiangsu, China
}

Supporting Information

ABSTRACT: The reaction of various organozinc pivalates with anthranils provides anilines derivatives, which cyclize under acidic conditions providing condensed quinolines. Using alkenylzinc pivalates, electron-rich arylzinc pivalates or heterocyclic zinc pivalates produces directly the condensed quinolines of which several structures belong to new heterocyclic scaffolds. These $\mathrm{N}$-heterocycles are of particular interest for organic light emitting diodes with their high photoluminescence quantum yields and long exciton lifetimes as well as for hole-transporting materials in methylammonium lead iodide perovskites solar cells due to an optimal band alignment for holes and a large bandgap.

$\mathrm{C}$ ondensed N-heterocycles are important molecules for material science applications. ${ }^{1}$ Although, several synthetic methods have been developed for the preparation of condensed $\mathrm{N}$-heterocycles, there is a lack of generality in such methods, especially for the preparation of condensed quinolines of type 1 , which are of interest as new materials. ${ }^{1}$ Organometallics reagents are very useful for constructing heterocyclic scaffolds, ${ }^{2}$ especially organozinc reagents have found wide applications. ${ }^{3}$ Organozinc pivalates are a class of zinc organometallics with enhanced air and moisture-stability, which can be stored for months as solids under argon. ${ }^{4}$ Recently, we have reported a new cobalt-catalyzed electrophilic amination using the reaction of organozinc pivalates ${ }^{5}$ with hydroxylamine benzoates. ${ }^{6,7}$ Compared to Pd- or Ni- catalysts, the use of cobalt salts ${ }^{8}$ was preferred for toxicity and price considerations. $^{9}$ This amination had a broad reaction scope and proceeded under mild reaction conditions. Herein, we report an extension of this amination using readily accessible anthranils ${ }^{10}$ of type 2 as electrophilic reaction partner.

We envision that anthranils 2 could react (formally via resonance structure 3 , eq 1) with alkenyl-, aryl- or heteroaryl-

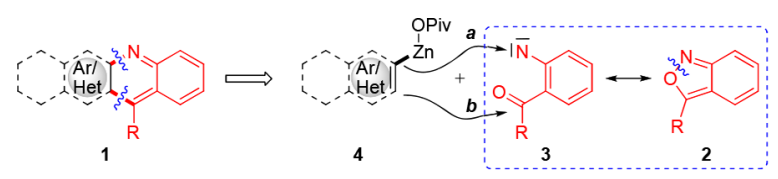

zinc pivalates 4 (step a) to provide after a Friedel-Crafts reaction (step b) condensed quinoline structures of type 1 . Preliminary experiments show that PhZnOPiv (4a) reacts best with anthranil (2a) in the presence of $10 \mathrm{~mol} \%$ of $\mathrm{CoCl}_{2}$ at 23 ${ }^{\circ} \mathrm{C}$ for $16 \mathrm{~h}$ to provide the amino-aldehyde $5 \mathrm{a}$ in $65 \%$ isolated yield. Other transition-metal salts, such as $\mathrm{CrCl}_{2}, \mathrm{MnCl}_{2}, \mathrm{FeCl}_{2}$ or $\mathrm{Fe}(\mathrm{acac})_{3}$ gave no product (Table 1 , entries $\left.1-7\right) .{ }^{11}$ Using

Table 1. Optimization for Cobalt-Catalyzed Amination Using Anthranils (2a) ${ }^{a}$

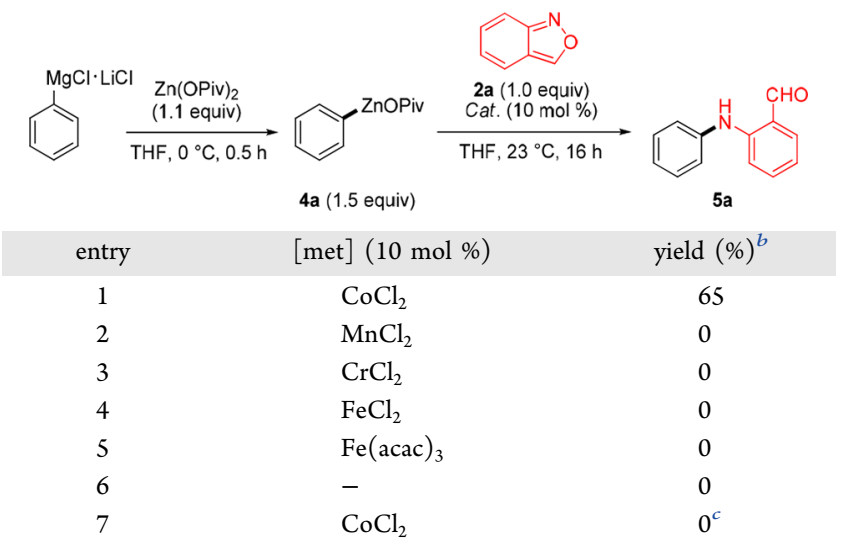

${ }^{a}$ Reaction conditions: $4 \mathrm{a}(0.75 \mathrm{mmol}), 2 \mathrm{a}(0.50 \mathrm{mmol})$, [cat.] (10 mol \%), THF (2.0 mL), $23{ }^{\circ} \mathrm{C}, \mathrm{N}_{2}, 16$ h. ${ }^{b}$ Isolated yields. ${ }^{c} \mathrm{PhMgCl}$ (1.5 equiv) was used.

these conditions, we have prepared a range of amino-aldehydes $(\mathbf{5 b}-\mathbf{5 f})$ and amino-ketones $(\mathbf{5 g}-\mathbf{5 k})$ in $56-91 \%$ yields (Scheme 1). Organozinc pivalates were the best nucleophiles, although arylalanes of type $\mathrm{ArAlEt}_{2}$ can also be used. ${ }^{12}$ Also, heterocyclic zinc pivalates derived from the pyrazole and indole scaffolds produce the expected aniline derivatives $\mathbf{5 1}$ and $5 \mathrm{~m}$ in $55-75 \%$ yields. Moreover, ferrocenylzinc pivalate, as well as methyl- or benzylzinc pivalates smoothly delivered the corresponding anilines $\mathbf{5 n}-\mathbf{5 p}$ in $40-79 \%$ yields.

The treatment of aniline derivatives of type 5 in TFA for 12 $\mathrm{h}$ at $80{ }^{\circ} \mathrm{C}$ provides the corresponding acridines $(6 \mathrm{a}-6 \mathrm{c})$ in excellent yields (Scheme 2).

We have extended this preparation of quinoline derivatives by treating various anthranils (2) with alkenylzinc pivalates ${ }^{13}$ under our standard conditions. To our delight, we observed after the electrophilic amination step, an cycloisomerisation

Received: October 24, 2018

Published: December 18, 2018 
Scheme 1. Amino-Aldehydes and Amino-Ketones of Type 5 Obtained by Cobalt-Catalyzed Reaction of Organozinc Pivalates 4 with Anthranils 2

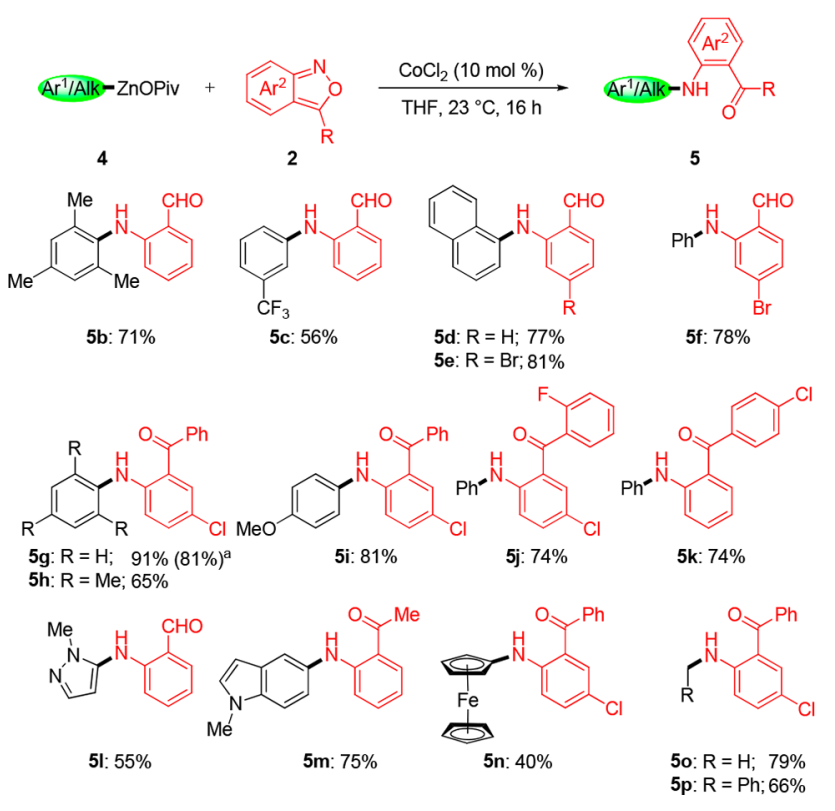

${ }^{a} \mathrm{PhAl}(\mathrm{Et})_{2}$ (1.5 equiv) was used as nucleophile.

Scheme 2. Condensed N-Heterocycles Prepared from Anilines of Type 5
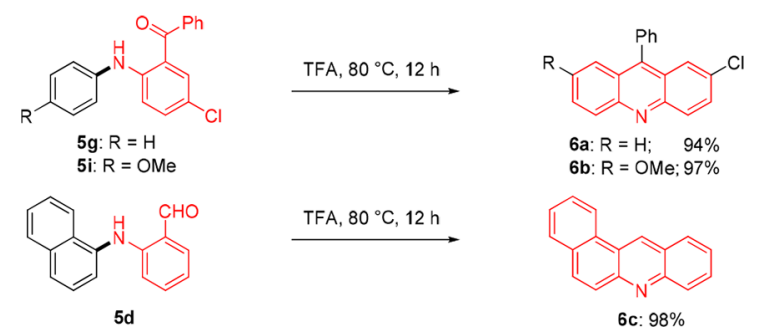

which in a one-pot procedure provided the quinolines $8 \mathbf{a}-\mathbf{8 n}$ in $62-96 \%$ yields (Scheme 3).

Furthermore, we have extended this new quinoline synthesis using aryl and heterocylic zinc pivalates $\mathbf{9}$, which were prepared

Scheme 3. Cobalt-Catalyzed Amination of Alkenylzinc Pivalates (7) with Anthranils (2)

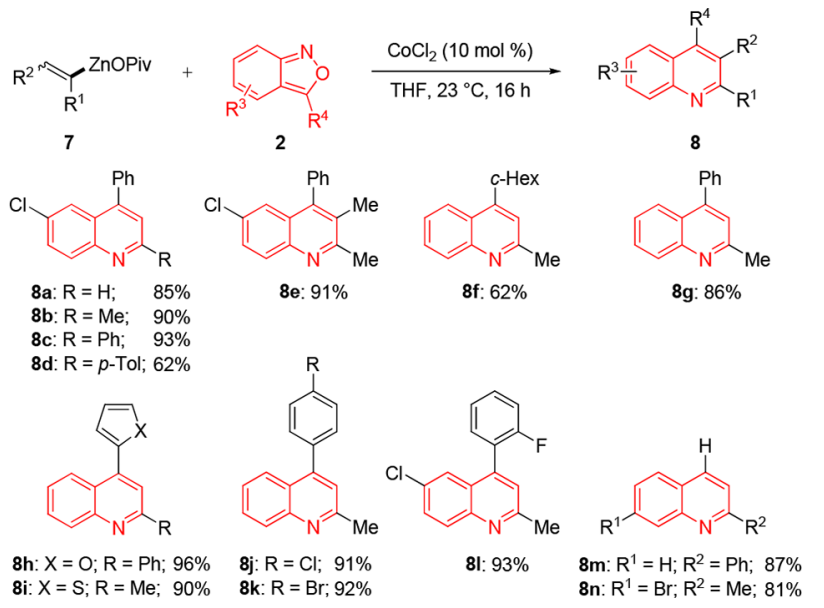

from the corresponding (hetero)aryl bromides by $\mathrm{Mg}$ insertion in the presence of $\mathrm{LiCl}^{14}(\mathbf{9 a}-\mathbf{9 g})$, or by a directed metalation of heterocyclic substrates with TMP-bases (TMP = 2,2,6,6-tetramethylpiperidyl ${ }^{15}$ such as TMPZnOPiv $\cdot \mathrm{LiCl}^{16}$ or TMPMgCl$\cdot \mathrm{LiCl}^{17}(\mathbf{9 h}-\mathbf{9 n})$, followed by transmetalation with $\mathrm{Zn}(\mathrm{OPiv})_{2}$. By using especially electron-rich organozinc pivalates, we have observed using our standard conditions, that after amination a cyclization occurs (via $\mathbf{A}$ and $\mathbf{B}$ in Table 2) leading to various condensed $\mathrm{N}$-heterocyclic derivatives $10 \mathrm{a}-10 \mathrm{p}$. In several cases, fully new types of heterocycles were obtained (101-10p). Of special interest for material applications may be the TTF-derived heterocycle ${ }^{18} \mathbf{1 0 m}$ (entry 13), as well as the related sulfur-contained heterocycles $^{19} 10$ n to 10 p (entries 14-16).

Furthermore, we have shown that some of these heterocycles can be further functionalized by metalation. Thus, the condensed heterocycles $10 \mathrm{~m}$ and $10 \mathrm{f}$ were treated with $\mathrm{TMPMgCl} \cdot \mathrm{LiCl}$ at $23{ }^{\circ} \mathrm{C}$ for $16 \mathrm{~h}$ to give complete magnesiation (as shown by iodolysis). ${ }^{12,17}$ Addition of $\mathrm{Zn}$ (OPiv) ${ }_{2}$ followed by a Negishi cross-coupling using XPhos $^{20}$ gave the arylated N-heterocycle bond. ${ }^{5 \mathrm{~d}}$ Also a Buchwald-Hartwig amination ${ }^{21}$ of $\mathbf{1 0 g}$ provided the aminated thieno[2,3-b] quinoline $\mathbf{1 3}$ in $72 \%$ yield. Interestingly, the zinc pivalate derived from thieno[2,3-b]quinoline (10f) reacted again with anthranil (4a) in the presence of $\mathrm{CoCl}_{2}(10 \mathrm{~mol} \%)$ furnishing the new heterocycle 14 in 34\% yield (Scheme 4 ).

In order to gain insights about the electronic structures of these heterocycles, we analyzed the optical properties and performed in some cases additional cyclovoltammetry measurements. Studies about the optical features of these $\mathrm{N}$ heterocycles can allow for the preparation of tailor-made molecules with optimum optical properties. All compounds showed a strong absorption in the UV region whereas careful tuning or functionalization of the quinoline backbone allowed extending the absorption toward the visible range. ${ }^{12}$ This was achieved by simply increasing the size of the chromophore, exchanging the heteroatoms or inserting functional groups such as a methoxy group. In the case of $\mathbf{6 a}$ and $\mathbf{6 b}$, it was noticed that the insertion of a methoxy group at the acridine body leads to a small redshift and an increased absorption of wavelengths longer than $300 \mathrm{~nm}$ (Figure 1a). When comparing $10 \mathrm{~d}, 10 \mathrm{e}$ and $10 \mathrm{f}$ or $10 \mathrm{j}$ and $10 \mathrm{k}$, it was observed that the exchange of oxygen heteroatoms with sulfur leads to a redshift of the absorption which results in a $0.3 \mathrm{eV}$ reduced bandgap (see Supporting Information). ${ }^{22,23}$ This was explained by the higher electronegativity of oxygen which led to a more localized electron density and subsequently a loss of aromaticity of the heterocycles. For the sulfur containing heterocycles, the better aromaticity led to larger $\pi$-systems and thus absorption of longer wavelengths.

Upon excitation at $378 \mathrm{~nm}$ the compounds showed photoluminescence (PL) in the range of 400 to $570 \mathrm{~nm}$. The strongest emission was found for $\mathbf{6 b}$ at $510 \mathrm{~nm}$ followed by 10b, 10a, 6a and 14 with their maxima at 482, 398, 494 and $434 \mathrm{~nm}$, respectively. Additionally, a significant red-shift was observed for the PL maxima of $10 \mathrm{~m}$ compared to $10 \mathrm{o}$, which was attributed to the larger $\pi$-system and the TTF-scaffold (Figure 1b). We measured the photoluminescence quantum yields (PLQY) of the heterocycles whereby the highest PLQY of $37 \%$ was observed for compound $\mathbf{6} \mathbf{b}$, followed by the other acridine containing heterocycles $\mathbf{1 0 b}(26 \%)$ and $\mathbf{6 a}(15 \%)$. The other heterocycles showed only moderate PLQY below $5 \%{ }^{12}$ Interestingly, the compounds with the strongest PL were 
Table 2. Substrate Scope of (Hetero)arylzinc Pivalates 9 Leading to Condensed N-Heterocycles Type 10

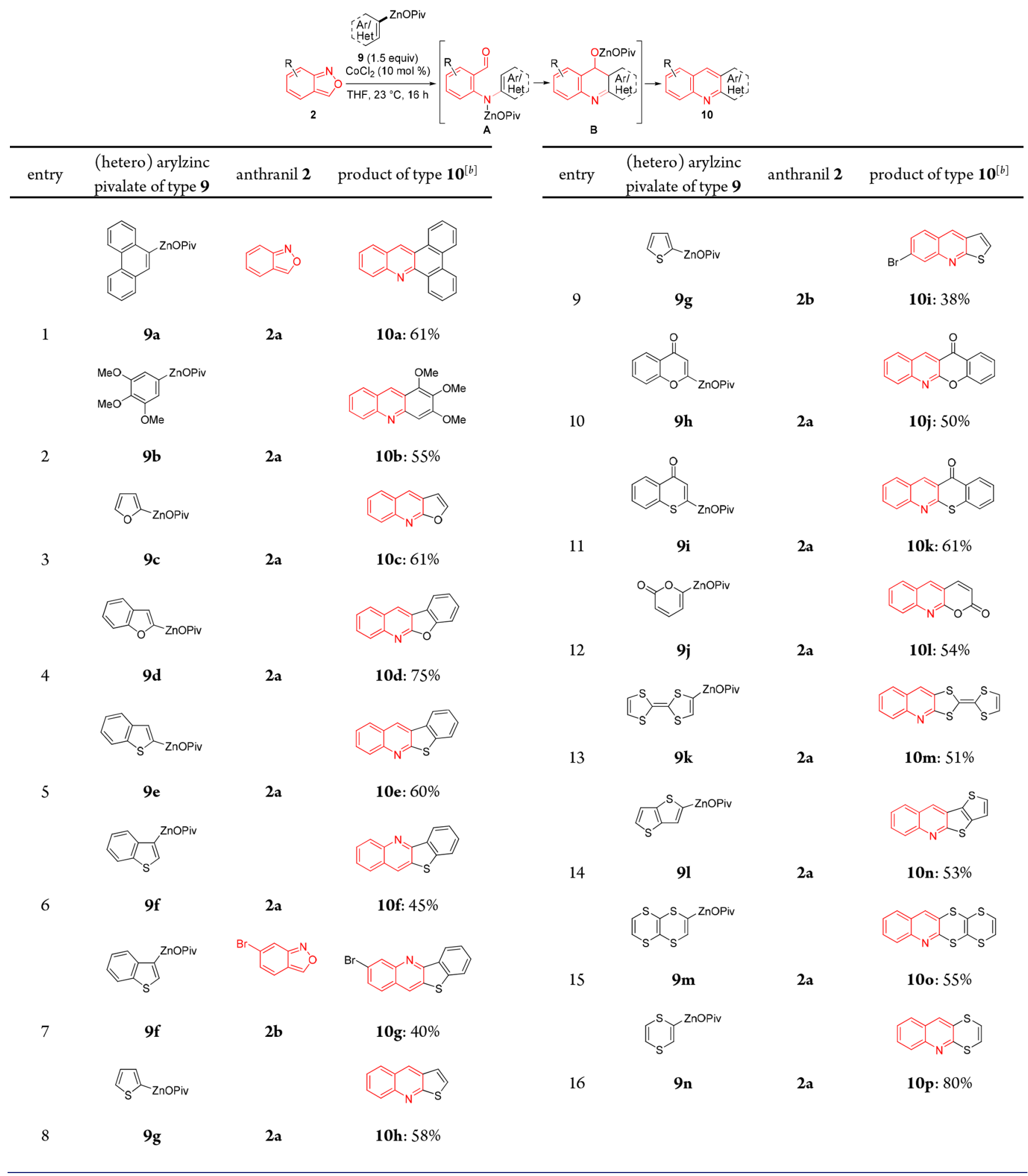

all containing an acridine core unit. Furthermore, by just flipping a thiophene unit in compound 10e, i.e., the sulfur and nitrogen heteroatoms were not in neighboring position but on opposite sites (10f), the PL position and intensity as well as the lifetimes did drastically change. In this fashion, it is possible to tune PL properties without changing the absorption bands and bandgap considerably. ${ }^{12}$ The longest PL decay times were measured on $10 \mathrm{~b}$ with an acridine core and three methoxy groups. Furthermore, the PL lifetimes of $\mathbf{6 b}$ were more than doubled compared to $\mathbf{6 a}$ which is missing a methoxy group. Also interesting was the fact that the TTF-scaffold in $10 \mathrm{~m}$ resulted in one of the fastest PL decays (Figure 1c). These results give an indication that the inserted methoxy groups are of great advantage to increase PL lifetimes. Regarding the overall emission properties of the studied N-heterocycles, applications in the field of OLEDs are promising. Materials for 
Scheme 4. Late-Stage Functionalizations of N-Heterocycles
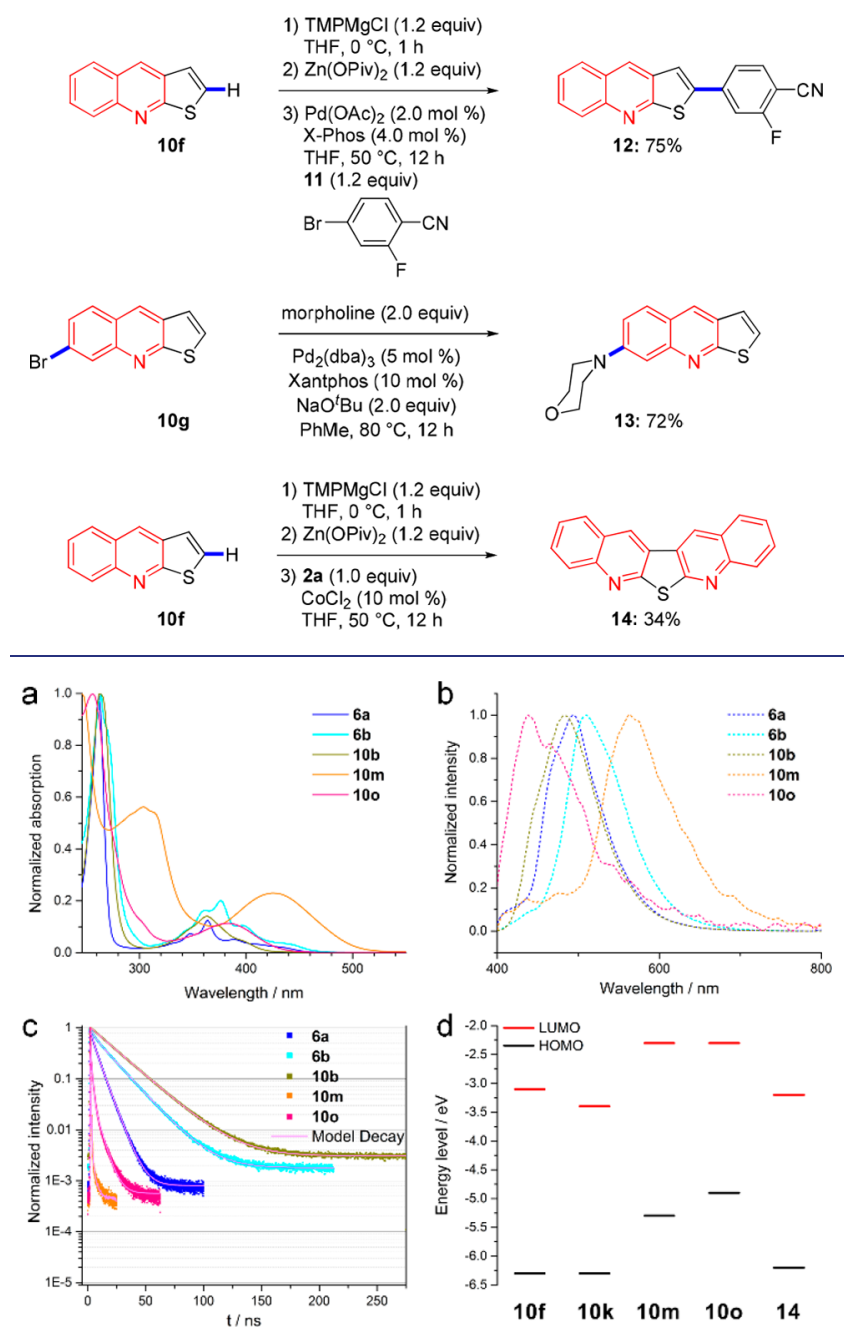

Figure 1. (a) Absorption spectra, (b) photoluminescence spectra and (c) time-correlated single photon counting in solution $(50 \mu \mathrm{M}$ in DCM). (d) Energy levels of selected condensed N-heterocycles obtained by CV measurements and optical bandgap.

OLEDs require, among other properties, a long PL lifetime and high PL quantum yield, i.e., low nonradiative recombination loss, in order to provide high device efficiencies. ${ }^{24,25}$ In our study, compound $\mathbf{6 b}$ was found to be a promising candidate for OLEDs with a high PL quantum yield and long lifetimes. Our values are comparable with reports in the literature, particularly for materials based on singlet emission (fluorescence). ${ }^{24,26-28}$ On the basis of these results, one can even improve or tailor-design the desired features by adding new or different functional groups, such as methoxy groups, which would be part of further studies.

In order to investigate the energy levels of compounds 10f, $10 \mathrm{k}, 10 \mathrm{~m}, 10 \mathrm{o}$ and 14 , we performed cyclic voltammetry $(\mathrm{CV})$ measurements. The energy for the highest occupied molecular orbital (HOMO) was extracted from forward scans in an acetonitrile solution using the internal standard ferrocene with a potential of $E\left(\mathrm{Fc} / \mathrm{Fc}^{+}\right)=-4.8 \mathrm{eV}$ vs $E_{\mathrm{vac}}{ }^{29}$ The HOMO levels for 10f, 10k and 14 were found to be in the same region around $-6.3 \mathrm{eV}$, whereas $10 \mathrm{~m}$ and $10 \mathrm{o}$ exhibit significantly higher HOMO energies with -4.9 and $-5.3 \mathrm{eV}$, respectively. The TTF-derived heterocycle displayed the highest HOMO, which is in good agreement with results from the literature (Figure 1d). ${ }^{18 \mathrm{c}}$ Solely from the energy level of compound $10 \mathrm{~m}$ and 10o, the alignment would be suitable for an application as hole transporting material in organic photovoltaics (OPVs) or in the case of $\mathbf{1 0 0}$ for perovskite solar cells. For the latter, not only the HOMO is in good alignment with the commonly used methylammonium lead iodide (MAPI) perovskite, but also the LUMO value is high enough to effectively block electrons. The large bandgap also implies that no visible light is absorbed which will hence not diminish the light to be absorbed by the active layer. $^{30}$

In summary, we have reported a convenient cobalt-catalyzed amination using various anthranils and functionalized aryl-, heteroaryl-, alkenyl- and alkyl-zinc pivalates under mild reaction conditions. This method gives an access to condensed $\mathrm{N}$-heterocycles, of which several are new heterocyclic scaffolds. The optical characterization of the condensed N-heterocycles revealed promising properties for applications such as organic light emitting diodes or hole-transporting materials, e.g., in perovskite solar cells. Further extensions of the method are currently underway in our laboratory and will provide a broad set of potential building blocks for new materials.

\section{ASSOCIATED CONTENT}

\section{S Supporting Information}

The Supporting Information is available free of charge on the ACS Publications website at DOI: 10.1021/jacs.8b11466.

General remarks, optimization tables, additional experiments, representative procedures, characterization data of 5, 6, 8, 10-14 and NMR spectra (PDF)

Methods, UV-vis spectroscopy and photoluminescence spectroscopy, Tauc plots, photoluminescence quantum yield, time-correlated single photon counting, and cyclic voltammetry and energy levels of HOMO and LUMO (PDF)

\section{AUTHOR INFORMATION}

\section{Corresponding Authors}

*jjackli@jiangnan.edu.cn

*tbein@cup.uni-muenchen.de

*paul.knochel@cup.uni-muenchen.de

ORCID

Jie Li: 0000-0002-6912-3346

Niklas Keller: 0000-0003-1581-072X

Andreas C. Jakowetz: 0000-0001-7804-7210

Thomas Bein: 0000-0001-7248-5906

Paul Knochel: 0000-0001-7913-4332

\section{Author Contributions}

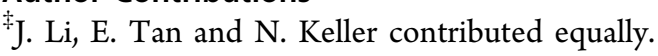

Notes

The authors declare no competing financial interest.

\section{ACKNOWLEDGMENTS}

We thank the Deutsche Forschungsgemeinschaft (DFG), excellent initiative e-conversion (LMU) and the National Natural Science Foundation of China (Grant No. 21602083) for financial support. We also thank the Fundamental Research Funds for the Central Universities (JUSRP51703A). The research leading to these results has received funding from the European Research Council under the European Union's 
Seventh Framework Programme (FP7/2007-2013)/ERC grant agreement no. 321339 .

\section{REFERENCES}

(1) (a) Bunz, U. H. F.; Engelhart, J. U.; Lindner, B. D.; Schaffroth, M. Large N-heteroacenes: new tricks for very old dogs. Angew. Chem., Int. Ed. 2013, 52, 3810-3821. (b) Bunz, U. H. F. The larger linear Nheteroacenes. Acc. Chem. Res. 2015, 48, 1676-1686.

(2) (a) Eicher, T.; Hauptmann, S. The Chemistry of Heterocycles, 2nd ed.; Wiley-VCH: Weinheim, Germany, 2003. (b) Joule, J. A.; Mills, K. Heterocyclic Chemistry, 4th ed.; Blackwell Science: Oxford, U. K., 2000. Selected examples: (c) Bartoli, G.; Palmieri, G.; Bosco, M.; Dalpozzo, $\mathrm{R}$. The reaction of vinyl grignard reagents with 2 -substituted nitroarenes: a new approach to the synthesis of 7-substituted indoles. Tetrahedron Lett. 1989, 30, 2129-2132. (d) Frischmuth, A.; Knochel, P. Preparation of functionalized indoles and azaindoles by the intramolecular copper-mediated carbomagnesiation of ynamides. Angew. Chem., Int. Ed. 2013, 52, 10084-10088. (e) Gati, W.; Couty, F.; Boubaker, T.; Rammah, M. M.; Rammah, M. B.; Evano, G. Intramolecular carbocupration of $\mathrm{N}$-aryl-ynamides: a modular indole synthesis. Org. Lett. 2013, 15, 3122-3125. (f) Nickel, J.; Fernandez, M.; Klier, L.; Knochel, P. Synthesis of pyrrolo[2,3-d]pyrimidines by copper-mediated carbomagnesiations of $\mathrm{N}$-sulfonyl ynamides and application to the preparation of rigidin $\mathrm{A}$ and a 7 -azaserotonin derivative. Chem. - Eur. J. 2016, 22, 14397-14400.

(3) Reviews: (a) Chen, Y.-H.; Ellwart, M.; Malakhov, V.; Knochel, P. Solid organozinc pivalates: a new class of zinc organometallics with greatly enhanced air- and moisture-stability. Synthesis 2017, 49, 3215-3223. (b) Haas, D.; Hammann, J. M.; Greiner, R.; Knochel, P. Recent developments in Negishi cross-coupling eeactions. ACS Catal. 2016, 6, 1540-1552. and references cited therein.

(4) Hernán-Gómez, A.; Herd, E.; Hevia, E.; Kennedy, A. R.; Knochel, P.; Koszinowski, K.; Manolikakes, S. M.; Mulvey, R. E.; Schnegelsberg, C. Organozinc pivalate reagents: segregation, solubility, stabilization, and structural insights. Angew. Chem., Int. Ed. 2014, 53, 2706-2710.

(5) Selected examples: (a) Greshock, T. J.; Moore, K. P.; McClain, R. T.; Bellomo, A.; Chung, C. K.; Dreher, S. D.; Kutchukian, P. S.; Peng, Z.; Davies, I. W.; Vachal, P.; Ellwart, M.; Manolikakes, S. M.; Knochel, P.; Nantermet, P. G. Synthesis of complex druglike molecules by the sse of highly functionalized bench-stable organozinc reagents. Angew. Chem., Int. Ed. 2016, 55, 13714-13718. (b) Manolikakes, S. M.; Ellwart, M.; Stathakis, C. I.; Knochel, P. Air-stable solid aryl and heteroaryl organozinc pivalates: syntheses and applications in organic synthesis. Chem. - Eur. J. 2014, 20, 1228912297. (c) Stathakis, C. I.; Manolikakes, S. M.; Knochel, P. TMPZnOPiv॰LiCl: a new base for the preparation of air-stable solid zinc pivalates of sensitive aromatics and heteroaromatics. Org. Lett. 2013, 15, 1302-1305. (d) Colombe, J. R.; Bernhardt, S.; Stathakis, C.; Buchwald, S. L.; Knochel, P. Synthesis of solid 2pyridylzinc reagents and their application in Negishi reactions. Org. Lett. 2013, 15, 5754-5757. (e) Stathakis, C. I.; Bernhardt, S.; Quint, V.; Knochel, P. Improved air-stable solid aromatic and heterocyclic zinc reagents by highly selective metalations for Negishi crosscouplings. Angew. Chem., Int. Ed. 2012, 51, 9428-9432.

(6) Chen, Y. H.; Grassl, S.; Knochel, P. Cobalt-catalyzed electrophilic amination of aryl- and heteroarylzinc pivalates with $\mathrm{N}$ hydroxylamine benzoates. Angew. Chem., Int. Ed. 2018, 57, 11081111.

(7) Other electrophilic aminations through $\mathrm{N}-\mathrm{O}$ or $\mathrm{N}-\mathrm{Cl}$ bond cleavage, such as hydroxylamine benzoates, oxaziridines and chloroamines: (a) Gao, H.; Zhou, Z.; Kwon, D.-H.; Coombs, J.; Jones, S.; Behnke, N. E.; Ess, D. H.; Kürti, L. Rapid heteroatom transfer to arylmetals utilizing multifunctional reagent scaffolds. Nat. Chem. 2017, 9, 681-688. (b) Zhou, Z.; Ma, Z.; Behnke, N. E.; Gao, H.; Kürti, L. Non-deprotonative primary and secondary amination of (hetero)arylmetals. J. Am. Chem. Soc. 2017, 139, 115-118. (c) Liu, J.; Wu, K.; Shen, T.; Liang, Y.; Zou, M.; Zhu, Y.; Li, X.; Li, X.; Jiao, N. Fe-catalyzed amination of (hetero)arenes with a redox-active aminating reagent under mild conditions. Chem. - Eur. J. 2017, 23, 563-567. (d) Hendrick, C. E.; Bitting, K. J.; Cho, S.; Wang, Q. Siteselective copper-catalyzed amination and azidation of arenes and heteroarenes via deprotonative zincation. J. Am. Chem. Soc. 2017, 139, 11622-11628. (e) Zhou, S.; Yang, Z.; Chen, X.; Li, Y.; Zhang, L.; Fang, H.; Wang, W.; Zhu, X.; Wang, S. Copper-catalyzed electrophilic amination of organoaluminum nucleophiles with O-benzoyl hydroxylamines. J. Org. Chem. 2015, 80, 6323-6328. (f) McDonald, S. L.; Hendrick, C. E.; Wang, Q. Copper-catalyzed electrophilic amination of heteroarenes and arenes by $\mathrm{C}-\mathrm{H}$ zincation. Angew. Chem., Int. Ed. 2014, 53, 4667-4670. (g) Nguyen, M. H.; Smith, A. B. Coppercatalyzed electrophilic amination of organolithiums mediated by recoverable siloxane transfer agents. Org. Lett. 2013, 15, 4872-4875. (h) Qian, X.; Yu, Z.; Auffrant, A.; Gosmini, C. Cobalt-catalyzed electrophilic amination of arylzincs with N-chloroamines. Chem. - Eur. J. 2013, 19, 6225-6229. (i) Barker, T. J.; Jarvo, E. R. Titaniummediated amination of Grignard reagents using primary and secondary amines. Angew. Chem., Int. Ed. 2011, 50, 8325-8328. (j) He, C.; Chen, C.; Cheng, J.; Liu, C.; Liu, W.; Li, Q.; Lei, A. Aryl halide tolerated electrophilic amination of arylboronic acids with $\mathrm{N}$ chloroamides catalyzed by $\mathrm{CuCl}$ at room temperature. Angew. Chem., Int. Ed. 2008, 47, 6414-6417. (k) Kawano, T.; Hirano, K.; Satoh, T.; Miura, M. A new entry of amination reagents for heteroaromatic C$\mathrm{H}$ bonds: copper-catalyzed direct amination of azoles with chloroamines at room temperature. J. Am. Chem. Soc. 2010, 132, 69006901. (1) Barker, T. J.; Jarvo, E. R. Umpolung amination: nickelcatalyzed coupling reactions of $\mathrm{N}, \mathrm{N}$-dialkyl-N-chloroamines with diorganozinc reagents. J. Am. Chem. Soc. 2009, 131, 15598-15599. (m) Campbell, M. J.; Johnson, J. S. Mechanistic studies of the coppercatalyzed electrophilic amination of diorganozinc reagents and development of a zinc-free protocol. Org. Lett. 2007, 9, 1521-1524. See reviews: (o) Hendrick, C. E.; Wang, Q. Emerging developments using nitrogen-heteroatom bonds as amination reagents in the synthesis of aminoarenes. J. Org. Chem. 2017, 82, 839-847. (p) Dong, X.; Liu, Q.; Dong, Y.; Liu, H. Transition-metal-catalyzed electrophilic amination: application of O-benzoylhydroxylamines in the construction of the C-N bond. Chem. - Eur. J. 2017, 23, 24812511. (q) Yan, X.; Yang, X.; Xi, C. Recent progress in coppercatalyzed electrophilic amination. Catal. Sci. Technol. 2014, 4, 41694177. and references cited therein.

(8) (a) Knappke, C. E. I.; Grupe, S.; Gartner, D.; Corpet, M.; Gosmini, C.; Jacobi von Wangelin, A. Reductive cross-coupling reactions between two electrophiles. Chem. - Eur. J. 2014, 20, 68286842. (b) Cahiez, G.; Moyeux, A. Cobalt-catalyzed cross-coupling reactions. Chem. Rev. 2010, 110, 1435-1462. (c) Gosmini, C.; Begouin, J.-M.; Moncomble, A. Cobalt-catalyzed cross-coupling reactions. Chem. Commun. 2008, 3221-3233 and references cited therein. .

(9) (a) Egorova, K. S.; Ananikov, V. P. Angew. Chem., Int. Ed. 2016, $55,12150-12162$. (b) $\left[\mathrm{LD}_{50}\left(\mathrm{CoCl}_{2}\right.\right.$, rat oral $)=418 \mathrm{mg} / \mathrm{kg} ; \mathrm{LD}_{50}$ $\left(\mathrm{NiCl}_{2}\right.$, rat oral $)=186 \mathrm{mg} / \mathrm{kg} ; \mathrm{LD}_{50}\left(\mathrm{PdCl}_{2}\right.$, rat oral $\left.)=200 \mathrm{mg} / \mathrm{kg}\right]$.

(10) $\mathrm{C}-\mathrm{H}$ amination with anthranils: (a) Yu, S.; Tang, G.; Li, Y.; Zhou, X.; Lan, Y.; Li, X. Anthranil: an aminating reagent leading to bifunctionality for both $\mathrm{C}(\mathrm{sp} 3)-\mathrm{H}$ and $\mathrm{C}(\mathrm{sp} 2)-\mathrm{H}$ under rhodium(III) catalysis. Angew. Chem., Int. Ed. 2016, 55, 8696-9700. (b) Zou, M.; Liu, J.; Tang, C.; Jiao, N. Rh-catalyzed N-O bond cleavage of anthranil: a $\mathrm{C}-\mathrm{H}$ amination reagent for simultaneous incorporation of amine and a functional group. Org. Lett. 2016, 18, 3030-3033. (c) Wang, M.; Kong, L.; Wang, F.; Li, X. Rhodium-catalyzed amination and annulation of arenes with anthranils: $\mathrm{C}-\mathrm{H}$ activation assisted by weakly coordinating amides. Adv. Synth. Catal. 2017, 359, 4411-4416.

(11) The reaction of $\mathrm{PhZnCl}$ with $4 \mathrm{a}$ in the presence of $\mathrm{Ni}(\mathrm{acac})_{2}$ has been reported. Toxicity consideration of the use of nickel salts as well as more convenient reaction conditions led us prefer the use of $\mathrm{CoCl}_{2}$ as catalyst. See: Baum, J. S.; Condon, M. E.; Shook, D. A. Nickel-catalyzed transformations of 2,1-benzisoxazoles with organozinc reagents. J. Org. Chem. 1987, 52, 2983-2988.

(12) See the Supporting Information for details. 
(13) Li, J.; Knochel, P. Cobalt-catalyzed cross-couplings between alkenyl acetates and aryl or alkenyl zinc pivalates. Angew. Chem., Int. Ed. 2018, 57, 11436-11440.

(14) Piller, F. M.; Appukkuttan, P.; Gavryushin, A.; Helm, M.; Knochel, P. Convenient preparation of polyfunctional aryl magnesium reagents by a direct magnesium insertion in the presence of $\mathrm{LiCl}$. Angew. Chem., Int. Ed. 2008, 47, 6802-6806.

(15) (a) Uzelac, M.; Kennedy, A. R.; Hevia, E.; Mulvey, R. E. Transforming LiTMP lithiation of challenging diazines through Gallium alkyl trans-metal-trapping. Angew. Chem., Int. Ed. 2016, 55, 13147-13150. (b) McLellan, R.; Uzelac, M.; Kennedy, A. R.; Hevia, E.; Mulvey, R. E. LiTMP trans-metal-trapping of fluorinated aromatic molecules: a comparative study of aluminum and Gallium carbanion traps. Angew. Chem., Int. Ed. 2017, 56, 9566-9570. (c) Davin, L.; Clegg, W.; Kennedy, A. R.; Probert, M. R.; McLellan, R.; Hevia, E. Structural and synthetic insights into pyridine homocouplings mediated by a $\beta$-diketiminato Magnesium amide complex. Chem. Eur. J. 2018, 24, 14830-14835.

(16) (a) Stathakis, C. I.; Manolikakes, S. M.; Knochel, P. TMPZnOPiv $\bullet$ LiCl: a new base for the preparation of air-stable solid zinc pivalates of sensitive aromatics and heteroaromatics. Org. Lett. 2013, 15, 1302-1305. (b) Klier, L.; Bresser, T.; Nigst, T. A.; Karaghiosoff, K.; Knochel, P. Lewis acid-triggered selective zincation of chromones, quinolones, and thiochromones: application to the preparation of natural flavones and isoflavones. J. Am. Chem. Soc. 2012, 134, 13584-13587. (c) Mosrin, M.; Knochel, P. TMPZnCl. $\mathrm{LiCl}$ : a new active selective base for the directed zincation of sensitive aromatics and heteroaromatics. Org. Lett. 2009, 11, 1837-1840.

(17) (a) Balkenhohl, M.; Greiner, R.; Makarov, I. S.; Heinz, B.; Karaghiosoff, K.; Zipse, H.; Knochel, P. Zn-, Mg-, and Li-TMP bases for the successive regioselective metalations of the 1,5-naphthyridine scaffold. Chem. - Eur. J. 2017, 23, 13046-13050. (b) Jaric, M.; Haag, B. A.; Unsinn, A.; Karaghiosoff, K.; Knochel, P. Highly selective metalations of pyridines and related heterocycles using new frustrated lewis pairs or tmp-Zinc and tmp-Magnesium bases with $\mathrm{BF}_{3} \cdot \mathrm{OEt}_{2}$. Angew. Chem., Int. Ed. 2010, 49, 5451-5455. (c) Mosrin, M.; Bresser, T.; Knochel, P. Regio- and chemoselective multiple functionalization of chloropyrazine derivatives. application to the synthesis of coelenterazine. Org. Lett. 2009, 11, 3406-3409. (d) Krasovskiy, A.; Krasovskaya, V.; Knochel, P. Mixed $\mathrm{Mg} / \mathrm{Li}$ amides of the type $\mathrm{R}_{2} \mathrm{NMgCl} \cdot \mathrm{LiCl}$ as highly efficient bases for the regioselective generation of functionalized aryl and heteroaryl magnesium compounds. Angew. Chem., Int. Ed. 2006, 45, 2958-2961.

(18) (a) Gorgues, A.; Hudhomme, P.; Sallé, M. Highly functionalized tetrathiafulvalenes: riding along the synthetic trail from electrophilic alkynes. Chem. Rev. 2004, 104, 5151-5184. (b) Lorcy, D.; Bellec, N.; Fourmigué, M.; Avarvari, N. Tetrathiafulvalene-based group XV ligands: synthesis, coordination chemistry and radical cation salts. Coord. Chem. Rev. 2009, 253, 1398-1438. Example: (c) Nafe, J.; Auras, F.; Karaghiosoff, K.; Bein, T.; Knochel, P. Selective functionalization of tetrathiafulvalene using $\mathrm{Mg}$ - and $\mathrm{Zn}$-TMP-bases: preparation of mono-, di-, tri-, and tetrasubstituted derivatives. Org. Lett. 2015, 17, 5356-5359.

(19) Selected examples: (a) Castelló-Micó, A.; Nafe, J.; Higashida, K.; Karaghiosoff, K.; Gingras, M.; Knochel, P. Selective metalations of 1,4-dithiins and condensed analogues using TMP-magnesium and -zinc bases. Org. Lett. 2017, 19, 360-363. (b) Kunz, T.; Knochel, P. Selective multiple magnesiations of the thieno[3,2-b]thiophene scaffold. Chem. - Eur. J. 2011, 17, 866-872.

(20) X-Phos = 2-Dicyclohexylphosphino-2', $4^{\prime}, 6^{\prime}$-triisopropylbiphenyl; Martin, R.; Buchwald, S. L. Palladium-catalyzed Suzuki-Miyaura cross-coupling reactions employing dialkylbiaryl phosphine ligands. Acc. Chem. Res. 2008, 41, 1461-1473.

(21) Li, J.; Zhang, Z.; Tang, M.; Zhang, X.; Jin, J. Selective synthesis of isoquinolines by rhodium(III)-Catalyzed $\mathrm{C}-\mathrm{H} / \mathrm{N}-\mathrm{H}$ functionalization with $\alpha$-substituted ketones. Org. Lett. 2016, 18, 3898-3901.

(22) Fernandez, S.; Ganiek, M. A.; Karpacheva, M.; Hanusch, F. C.; Reuter, S.; Bein, T.; Auras, F.; Knochel, P. Synthesis and reactivity of triazaphenanthrenes. Org. Lett. 2016, 18, 3158-3161.
(23) Nafe, J.; Herbert, S.; Auras, F.; Karaghiosoff, K.; Bein, T.; Knochel, P. Functionalization of quinoxalines by using TMP bases: preparation of tetracyclic heterocycles with high photoluminescene quantum yields. Chem. - Eur. J. 2015, 21, 1102-1107.

(24) Jou, J.-H.; Kumar, S.; Agrawal, A.; Li, T.-H.; Sahoo, S. Approaches for fabricating high efficiency organic light emitting diodes. J. Mater. Chem. C 2015, 3, 2974-3002.

(25) Yersin, H.; Finkenzeller, W. J. Triplet Emitters for Organic Light-Emitting Diodes: Basic Properties. In Highly Efficient OLEDs with Phosphorescent Materials; Yersin, H., Ed.; WILEY-VCH Verlag GmbH \& Co. KGaA: Weinheim, Germany, 2008.

(26) Yao, L.; Zhang, S.; Wang, R.; Li, W.; Shen, F.; Yang, B.; Ma, Y. Highly Efficient Near-Infrared Organic Light-Emitting Diode Based on a Butterfly-Shaped Donor-Acceptor Chromophore with Strong Solid-State Fluorescence and a Large Proportion of Radiative Excitons. Angew. Chem., Int. Ed. 2014, 53, 2119-2123.

(27) Lo, M. Y.; Zhen, C.; Lauters, M.; Jabbour, G. E.; Sellinger, A. Organic-Inorganic Hybrids Based on Pyrene Functionalized Octavinylsilsesquioxane Cores for Application in OLEDs. J. Am. Chem. Soc. 2007, 129, 5808-5809.

(28) Hughes, G.; Bryce, M. R. Electron-transporting materials for organic electroluminescent and electrophosphorescent devices. J. Mater. Chem. 2005, 15, 94-107.

(29) Frost, J. M.; Faist, M. A.; Nelson, J. Energetic disorder in higher fullerene adducts: a quantum chemical and voltammetric study. $A d v$. Mater. 2010, 22, 4881-4884.

(30) Petrus, M. L.; Music, A.; Closs, A. C.; Bijleveld, J. C.; Sirtl, M. T.; Hu, Y.; Dingemans, T. J.; Bein, T.; Docampo, P. Design rules for the preparation of low-cost hole transporting materials for perovskite solar cells with moisture barrier properties. J. Mater. Chem. A 2017, 5, 25200-25210. 